\title{
Epidermal growth factor in the oesophagus
}

\author{
J Jankowski, G Coghill, B Tregaskis, D Hopwood, K G Wormsley
}

\begin{abstract}
Epidermal growth factor (EGF) has been implicated in mitogenesis and oncogenesis in the gastrointestinal tract. To determine the role of EGF in oesophageal disease, its quantity and distribution in the oesophageal mucosa of control subjects and patients with oesophageal disease were studied. Oesophageal biopsy specimens, taken $20-40 \mathrm{~cm}$ from the incisors in 72 patients, were graded histologically and adjacent specimens were taken for immunohistochemical analysis of the distribution of EGF. In patients with Barrett's columnar lined oesophagus, specimens were also taken from the gastric cardia for comparison. Twenty two biopsy specimens showed oesophagitis, 20 Barrett's mucosa, and 30 were histologically normal. EGF was found in the capillary endothelium of the normal oesophageal papillae and basal mucosa. Significantly more EGF positive papillae were found in the normal mucosa $(81 \%)$ than in the inflamed mucosa $(42 \%)(p<0.001)$. The 20 patients with Barrett's mucosa showed abnormal expression of EGF in $\mathbf{2 5 \%}$ of the isthmus and superficial epithelial cells. This study has shown that EGF is found only in the endothelial cells of the capillaries of the normal oesophageal mucosa and that the peptide is detectable significantly less frequently than normal in the inflamed oesophageal mucosa. EGF is also abnormally present, in large quantities, in the cytoplasm of the epithelial cells of Barrett's mucosa compared with gastric mucosa.
\end{abstract}

(Gut 1992; 33: 1448-1453)

Epidermal growth factor (EGF) is a single chain polypeptide that is secreted by submandibular glands, ${ }^{12}$ Brunner's glands in the duodenum, ${ }^{12}$ Paneth cells of the small intestine, ${ }^{3}$ and other exocrine glands, including the pancreas. ${ }^{+} \mathrm{EGF}$ is also found in 'a novel cell lineage containing neutral mucin' in the stomach and intestine adjacent to ulceration of the mucosa $a^{5}$ and in many gastrointestinal tumours. ${ }^{6-8}$ EGF is found in many body fluids, including saliva. ${ }^{239}$ Circulating concentrations are low, but high concentrations are found within platelet granules. ${ }^{23} 10$ 11 $\mathrm{By}$ binding to the EGF receptor, ${ }^{12}$ EGF exerts protean actions, including effects on wound healing, ${ }^{+1314}$ cellular proliferation, ${ }^{1213}$ differentiation, ${ }^{1516}$ and oncogenesis ${ }^{67-19}$ in the gastrointestinal tract. EGF has been reported to increase epithelial proliferation throughout the gastrointestinal tract $^{20-25}$ and also in other squamous epithelia including the skin. ${ }^{26}$
Whether there is a deficiency of secreted salivary EGF in patients with uncomplicated reflux oesophagitis is unknown, because reports have been contradictory. ${ }^{.728}$ In any case, the luminal route of action of EGF for maintaining oesophageal mucosal integrity seems unlikely since the oesophageal proliferative cells are situated in the basal layer. ${ }^{29} 30$

This study aimed to define the route whereby EGF gains access to the oesophageal epithelium, by immunohistochemical determination of the EGF distribution in biopsy specimens from healthy and diseased oesophageal mucosa, to determine whether it plays any role in the pathogenesis of oesophagitis.

\section{PATIENTS AND METHODS}

Twenty eight women and 24 men (mean age 48 years (range 20-77)) who attended an endoscopy clinic were studied, as were a further 20 patients (eight women and 12 men) (median age 67 years (range 42-81) who had proven Barrett's mucosa. All patients gave informed consent. None were taking non-steroidal anti-inflammatory drugs: 26 were taking ranitidine $150 \mathrm{mg}$ twice daily.

An oesophageal biopsy specimen was taken $20-40 \mathrm{~cm}$ from the incisors for histological examination. An immediately adjacent specimen was snap frozen in the endoscopy suite. Patients with Barrett's mucosa had three specimens taken from the area of columnar lined oesophagus and a fourth from the gastric cardia for comparison. Cryostat sections $(6 \mu \mathrm{m})$ were cut and EGF distribution was studied immunohistochemically. Monoclonal antibody (IgG) to EGF type 1 was supplied by Oncogene Science (Manhasset, NY, USA). This monoclonal antibody shows no cross reactivity with transforming growth factor alpha. ${ }^{3132}$ The avidin-biotin complex method followed by $\mathrm{DAB}$ visualisation were used to show the EGF-antibody complex. ${ }^{33}$

Negative control slides comprised normal oesophageal mucosa which had been treated with either avidin-biotin or EGF monoclonal antibody alone. In addition, we used absorbance experiments, incubating sections with purified EGF (BM, UK) at $10 \mu \mathrm{g} / \mathrm{ml}$. Sections of salivary glands containing EGF were used as positive controls.

Some sections were also stained immunohistochemically with polyclonal antibody to blood group factor $\mathrm{H}$ (Becton-Dickenson, UK). Blood group factor $\mathrm{H}$ has been reported to bind preferentially to endothelial cells as well as intestinal mucins and other glycoproteins. ${ }^{34}$

One of the authors (i) assessed the biopsy 
specimens and graded them according to the severity of histological inflammation (Jarvis criteria $^{35}$ and (ii) classified Barrett's mucosa according to the type of metaplasia ${ }^{36}$ - intestinal, junctional, or fundic. Sections of metaplastic mucosa that had a homogeneous pattern $(>90 \%$ mucosal surface) were selected. Dysplasia of the Barrett's mucosa was classified according to Riddell. ${ }^{37}$ Two observers independently assessed the EGF staining of the biopsy specimens without information about the histological status.

The percentage of positively stained papillae containing EGF endothelium in each biopsy specimen was calculated as a percentage of the total number of papillae.

The positive EGF staining of Barrett's mucosal biopsy specimens was graded according to a criteria that we have developed. ${ }^{8}$ Five randomly viewed areas of at least 400 , to a maximum of 1000 , consecutive nucleated epithelial cells in well orientated sections were independently assessed by two observers. The sections were considered positive only if the number of epithelial cells which had at least $1+$ staining was $>10 \%$ of the total epithelial cells. The intensity of staining was graded as $0-3$ (0 - no staining; $1+$ - weakly positive; $2+-$ moderately positive (cytoplasm positive but unstained cytoplasm also visible); and $3+-$ strongly positive (entire cytoplasm densely stained)). The grade considered to be $3+$ was stained as densely as simultaneously stained (control) submandibular tissue. In some sections with non-homogeneous staining, intensity per section was calculated. For example, if 500 cells were counted in one section and the number of cells of each intensity was as follows; $0=20$, $1=150,2=230,3=100$, the mean count was calculated as follows: $(0 \times 20)+(1 \times 150)+$ $(2 \times 230)+(3 \times 100)=910 / 500$ and the mean intensity in the section was rounded up to ' 2 '.

Sections of Barrett's mucosa were also stained to show neutral and acid mucous substances by the Alcian blue/diastase periodic acid Schiff method.

\section{STATISTICS}

The distribution of the data was Gaussian for normal and inflamed squamous oesophagitis and therefore analysis of variance was used to calculate the significance of intergroup distribution compared with intragroup variation to $95 \%$ confidence intervals. Because the distribution of the data from the Barrett's mucosa was not Gaussian the Kruskal-Wallis test was used to assess the variation between EGF expression in normal cardiac mucosa, Barrett's intestinal mucosa, and Barrett's junctional/cardiac mucosa. In addition, the Wilcoxon rank test was used to assess specifically the difference in EGF expression between Barrett's intestinal mucosa and Barrett's junctional/cardiac mucosa as well as between Barrett's mucosa with dysplasia and Barrett's mucosa without dysplasia.

\section{Results}

Thirty patients, 16 women and 14 men (median age 52 years) were subsequently shown to have

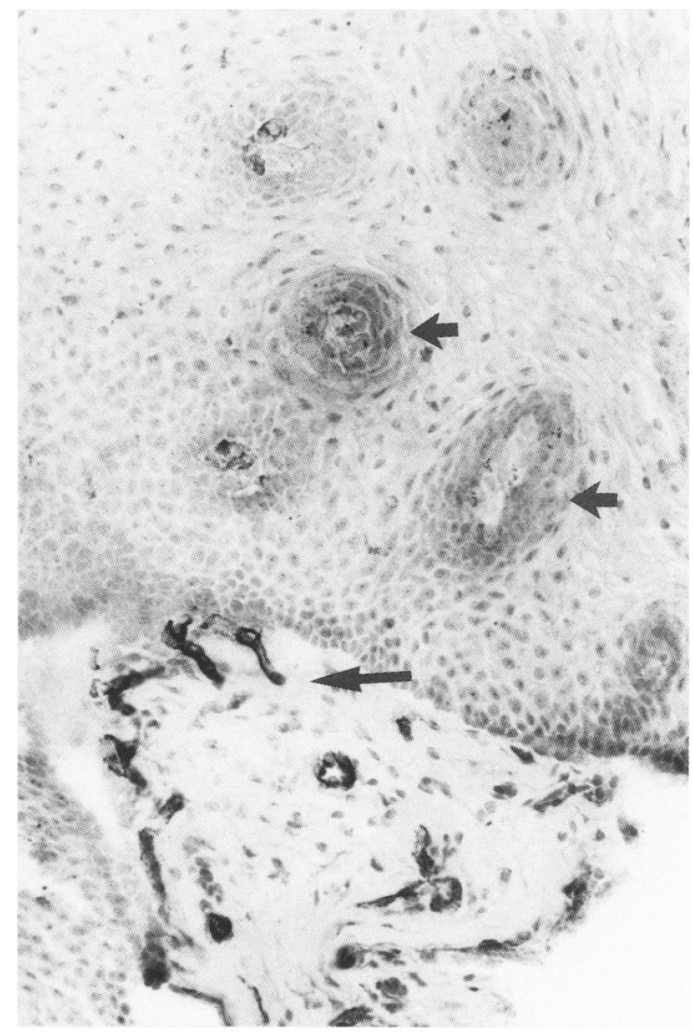

Figure 1: Photomicrograph of normal oesophageal mucosa cut in cross section and stained immunohistochemically with $E G F$ (original magnification $\times 100$ ). (The dark staining papillae contain $E G F$ containing endothelium (arrowed).)

both normal endoscopic and histological findings. Twenty two patients (12 women and 10 men) (median age 42 years) were subsequently shown to have oesophageal inflamation endoscopically and histologically.

Twenty biopsy specimens had previously been noted to show Barrett's mucosa.

Some sections incubated with EGF monoclonal antibody and EGF peptide showed minimal staining in the cytoplasm but this was less than grade 1 in our grading system and therefore did not interfere with our quantitation.

The cells in the squamous mucosa of the oesophagus that showed positive staining for EGF were confined to the capillary endothelial cells immediately adjacent to the basal cells of the papillae (Fig 1). The staining pattern was cytoplasmic in nature. There was no discernable staining of the mucosa in the control slides treated with either EGF or avidin-biotin complex alone. The glandular and ductal cells of the salivary glands stained strongly for EGF.

Serial sections in 10 patients stained for the presence of blood group factor $\mathrm{H}$ (Fig 2A) showed that the staining pattern detected all endothelium whereas (Fig 2B) not all blood vessels stained positively with EGF, only those in the lamina propria. When the sections were stained with elastase red and yellow (a marker of elastic fibres in the smooth muscle of vascular tissue) none of the EGF positive vessels were stained (not shown).

In sections from normal oesophageal mucosa, almost all the endothelium in the papillae stain positively for EGF (Fig 3A). On the other hand, sections from inflamed oesophageal mucosa contain little EGF in the capillary endothelium 


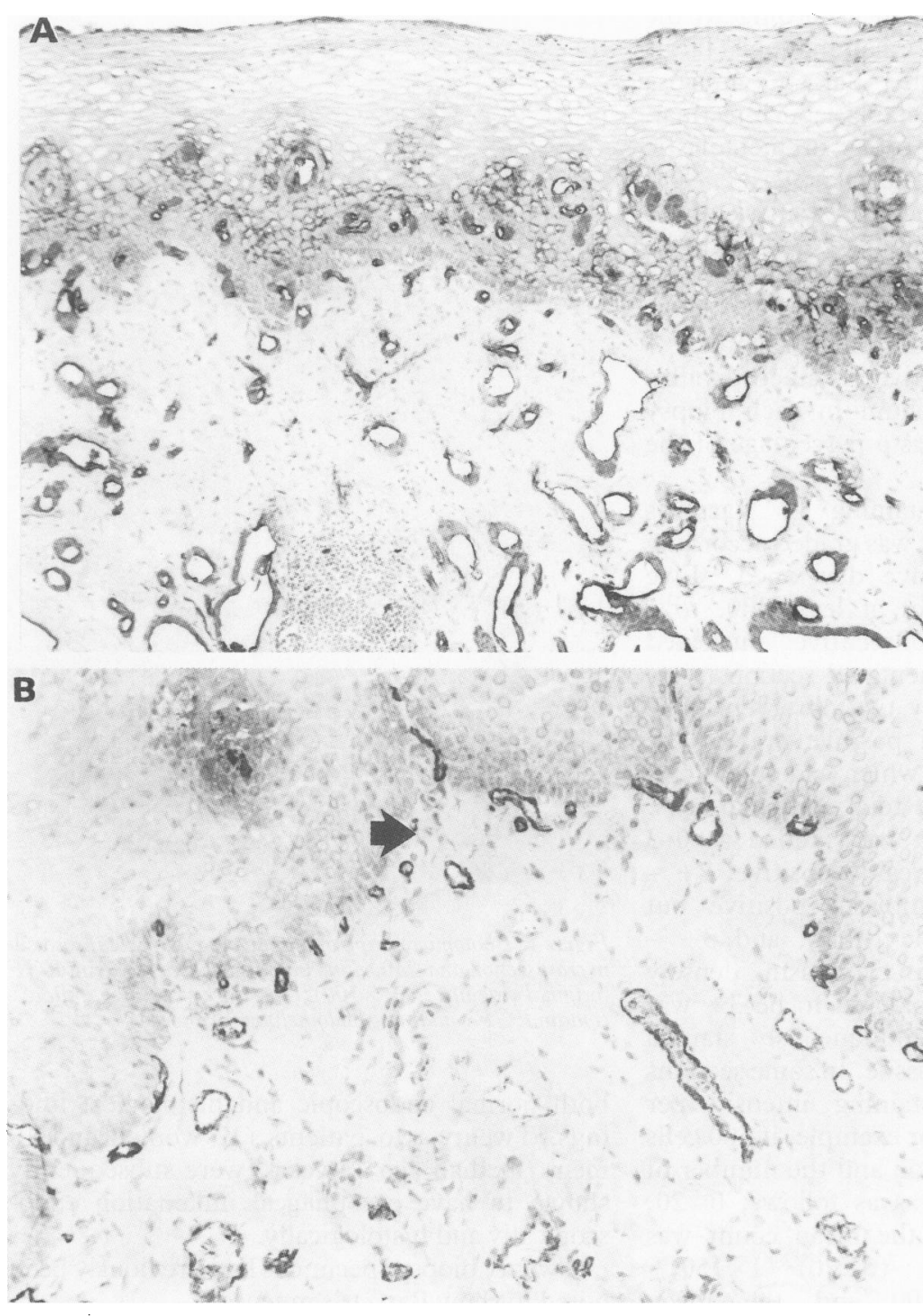

Figure 2: Both sections $(A$ and $B)$ are from sequential sections from the same biopsy specimen taken from a normal oesophagus. (A) Staining with blood group factor $H$ (original magnification $\times 40)$. (All capillaries stained positively.) (B) Staining with EGF (original magnification $\times 100)$. (Capillaries in the basal lamina are usually positively stained (arrowed).) while the other 15 had no dysplasia. Although the areas that stained positively for EGF corresponded well with the acid mucin or mixed mucin glands in intestinal-type mucosa, in the other types of Barrett's epithelium EGF stained strongly positive in an average of $25 \%$ (range 12 $34 \%$ ) of the superficial epithelial cells of the mucosa, irrespective of PAS staining (Fig 3B). Not all the glandular tissue in any section was positively stained, showing that the expression of EGF in Barrett's epithelium is not uniform. The staining of the epithelial cells is cytoplasmic, involving the basolateral and, to a lesser extent, the apical surfaces of the cells and EGF can also be seen in the mucus derived from the glandular ducts in many cases (Fig 3C). Although EGF was expressed to a greater degree in intestinal and fundic/junctional Barrett's mucosa than in gastric mucosa $(\mathrm{p}<0.01)$, there was no difference between the metaplastic types of Barrett's mucosa or the degree of dysplasia $(p=0.5)$ (Fig 6).

There was no difference between EGF expression in patients with uncomplicated reflux oesophagitis receiving treatment with ranitidine and those without therapy (median values 2 and 2, respectively) $(p=0 \cdot 8)$.

\section{Discussion}

There have been no previous reports of the occurrence or distribution of EGF in the healthy and inflamed squamous oesophagus, although we have described the occurrence of EGF in Barrett's mucosa. ${ }^{8}$ We have shown that the EGF antibody used in this study binds reliably to EGF peptide as reported by other workers. This study has shown that EGF can be found in the endothelial cells immediately adjacent to basal cell layers of the normal oesophagus, including those forming papillae. This is in keeping with previous studies that have found EGF in the vascular endothelium immediately adjacent to basal cells in bile ducts, ${ }^{38}$ glomeruli, ${ }^{39}$ and human oral mucosa. ${ }^{+0}$ In normal oesophageal mucosa the distribution of EGF does not alter from proximal to distal oesophagus.

It is interesting to note that not all vascular endothelium stains with EGF. It seems that EGF is confined to the capillaries and is not found in the submucosal venules and arterioles.

This study has also shown there are significantly fewer EGF-positively staining endothelial cells in inflamed than in normal oesophageal mucosa, although the distribution of the EGF is similar in inflamed and normal mucosa. EGF is also found in the superficial epithelial cells in Barrett's oesophagus, a distribution which is quite different to that in the squamous mucosa.

The origin of the EGF found in the oesophageal endothelial cells has not been defined. It is possible that EGF is not produced in the oesophagus but is transported to the oesophageal mucosa by the blood stream, being released from the platelets and then transported into capillary endothelium. ${ }^{10}$ "It has been shown previously that EGF exerts greater trophic action when administered intravenously than via the luminal route. ${ }^{+1}$ Perhaps EGF is stored in the endothelial cells of the normal mucosa and when inflammacomposed of intestinal mucosa, contained acid mucin (blue colouration in cytoplasm) or glands with both acid and neutral mucin (purple colouration in the cytoplasm). On histological examination, five of the subjects with Barrett's mucosa had moderate or high grade dysplasia, 
Figure 3: (A) Epidermal growth factor $(E G F)$

staining in an area of

Barrett's columnar lined

oesophagus close to the

squamo-columnar junction

(original magnification

$\times 40$ ). (Note no EGF is

present in the inflamed

squamous mucosa (arrow A)

and although $E G F$ is visible

in the adjacent Barrett's

mucosa, only some of the

glands are stained (arrow

B). ) (B) $E G F$ staining in

Barrett's mucosa (original

magnification $\times 50$ ).

(Disorganised glandular

architecture is visible and in

addition positive $E G F$

staining is present mainly in

the upper half of the glands.

(C) EGF staining in

Barrett's mucosa (original

magnification $\times 150)$. (The

staining is predominately

cytoplasmic (arrow A).)

There is moderate

basolateral and to a lesser

extent apical staining, also

partly reflecting $E G F$

attached to $E G F$ receptors

on cell membranes (arrow

$B)$. It is notable that $E G F$ is

seen in the luminal mucus

(arrow $C$ ).

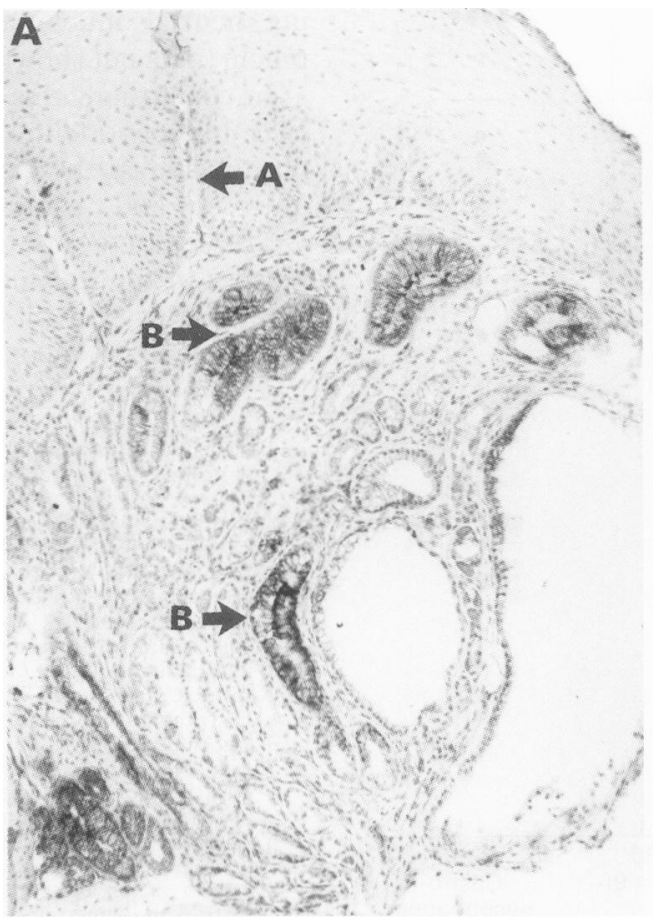

B

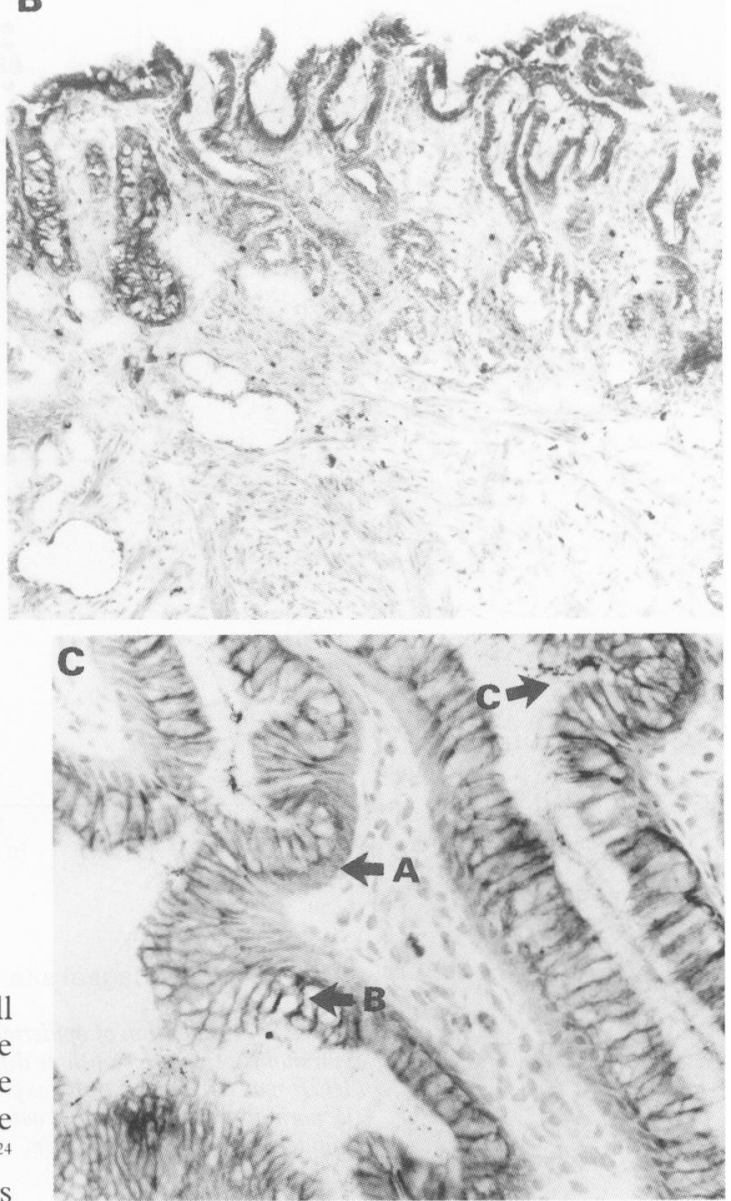

tion develops is rapidly utilised to stimulate proliferation because EGF is crucial for the change from quiescent cells to the $S$ phase of the proliferative cycle. ${ }^{29} \mathrm{EGF}$ is known to stimulate keratinocyte proliferation in vitro and in vivo. ${ }^{17} 2$ Our finding that EGF is depleted in oesophagitis is perhaps explained by a report that EGF has a relatively short duration of action $(<24$ hours $),{ }^{42}$ so that continual stimulation by fresh EGF is required to maintain a mitogenic response, depleting stores of EGF in the endothelial cells.

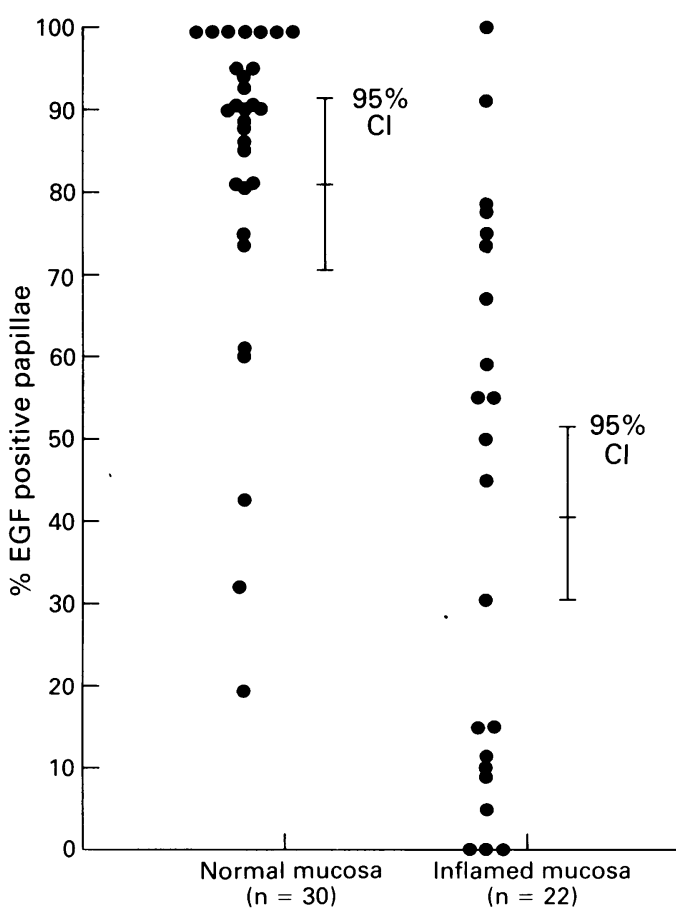

Figure 4: Distribution of epidermal growth factor $(E G F)$ positive papillae in normal and in inflamed oesophageal mucosa. (EGF staining in the papillae is decreased in squamous oesophagitis.) Means and $95 \%$ confidence intervals (CI) given.
Moreover we, and others, have also shown that the density of EGF receptors is maximal in the basal layer of the squamous oesophagus, which is the proliferative zone. ${ }^{+3+1}$

The assumption that the lower levels of EGF in oesophagitis are secondary to the oesophagitis has not yet been confirmed. The alternative that these lower levels are partly responsible for the development of oesophagitis - is also possible. EGF production is known to decrease with age. ${ }^{+2}$ Reduced production may reflect decreased delivery of EGF to the oesophageal mucosa, which may partly explain the increased incidence and severity of oesophagitis in the elderly.

Increased cellular proliferation has previously been reported in Barrett's mucosa,$^{45}$ and it is interesting to note that EGF is found in many of the epithelial cells of Barrett's epithelium. ${ }^{x}$ It has been proposed that the trophic and antisecretory effects of EGF are mediated by the luminal route in the stomach. ${ }^{+6+7}$ However, it has been stated that EGF does not stimulate the proliferation of gastric mucosal cells unless there is a breach of the mucosal lining. ${ }^{97+4}$ On the other hand, luminal EGF may be involved in the proliferative abnormalities of Barrett's mucosa because EGF receptors have been found throughout the glands of Barrett's mucosa. ${ }^{+}$

It is apparent from the present study that the EGF content of the different metaplastic and dysplastic types of Barrett's mucosa is similar. Therefore it seems that the EGF concentration in the cells does not explain the greater carcinogenic potential of mucosa with high grade dys- 


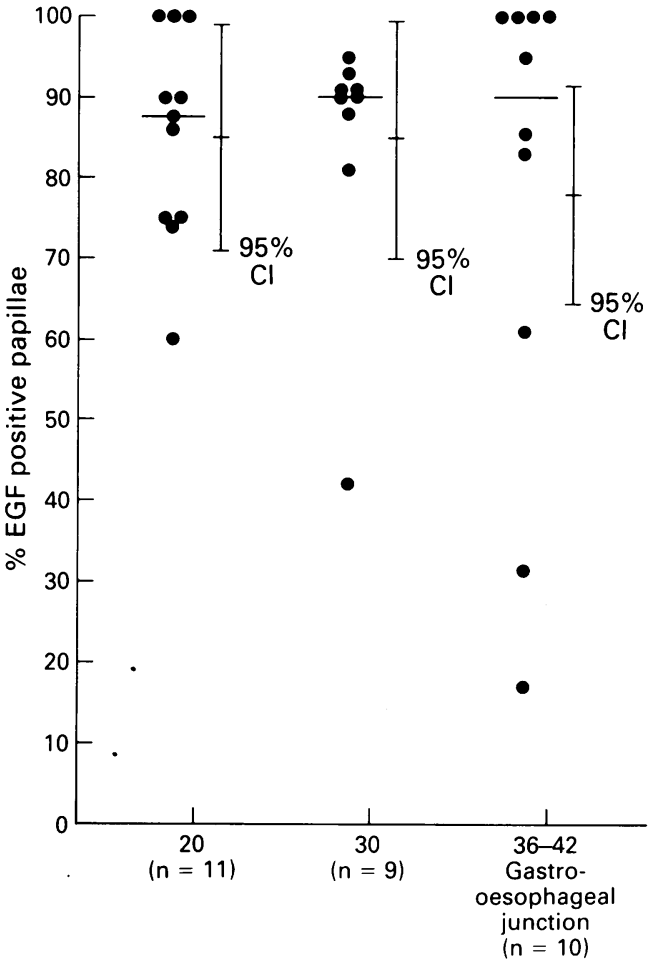

Oesophageal site ( $\mathrm{cm}$ from incisors)

Figure 5: Distribution of epidermal growth factor (EGF) immunohistochemistry at three different oesophageal sites ( $E G F$ was not differentially expressed at different sites from the normal proximal to distal oesophagus.) Means and 95\% confidence intervals $(C I)$ given.

plasia. In this context, it has been reported that over-expression of EGF in gastric mucosa is, by itself, unlikely to cause transformation without the simultaneous overproduction of the EGF receptor. ${ }^{+8-50}$

Some areas of intestinal type Barrett's mucosa contained predominantly acid mucin whereas all other forms of Barrett's mucosa contained neutral mucin (normal type of mucin in gastric mucosa). Wright et al have described EGF secreting lineages containing neutral mucin arising beside ulcerated intestinal mucosa. ${ }^{5} \mathrm{We}$ found no difference, however, between the expression of EGF in Barrett's mucosa contain-
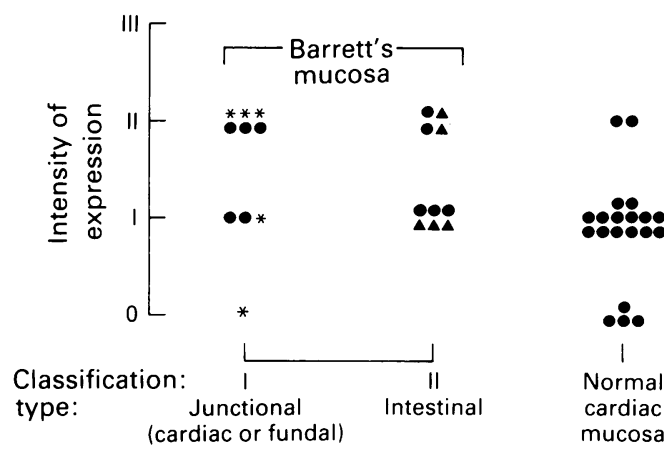

* Fundic type $\Delta$ Mucosa with dysplasia

Figure 6: Expression of epidermal growth factor $(E G F)$ in three different types of Barrett's epithelia. (EGF was not differentially expressed in the three types of Barrett's metaplasia.) ing neutral mucin and that containing acid mucin (data not shown).

In conclusion, this study has shown EGF or EGF-like peptide in the capillaries of the oesophagus and in the glandular tissue of Barrett's mucosa, and confirms previous reports. ${ }^{8+0}$ Decreased amounts of EGF are found in the mucosa of the inflamed oesophagus, indicating that EGF may also play a role in the development or healing of oesophagitis.

1 Bradshaw RR, Cavanaugh KP. Isolation and characterisation of growth factors - epidermal growth factor. In: Sporn M, Roberts A, eds. Peptide growth factors and their receptors I. Berlin: Springer-Verlag, 1990: 210-450.

2 Carpenter G, Wahl MI. The epidermal growth factor family. In: Sporn MB, Roberts AN, eds. Peptide growth factors and In: Sporn MB, Roberts AN, eds. Peptide growth factors and
their receptors II. London: Springer-Verlag, 1990: 430-570.

3 their receptors II. London: Springer-Verlag, 1990: $430-570$. epidermal growth factor levels in normal human gastroepidermal growth factor levels in normal hum

4 Konturek SJ, Bielanski W, Konturek SJ, Bogdal J, Olesksy J. Distribution and release of epidermal growth factor in man Gut 1989; 30: 1194-200.

5 Wright NA, Pike C, Elia G. Induction of a novel epidermal growth factor-secreting cell lineage by mucosal ulceration in human gastrointestinal stem cells. Natural 1990; 343: 82-5.

6 Yoshida K, Kyo E, Tetsuhiro T, Sano T, Niimoto M, Tahar E. Expression of epidermal growth factor, transforming growth factor alpha and their receptor genes in human gastric carcinomas; implication for autocrine growth. $\mathcal{f} p n \mathcal{F}$ Cancer Res 1990; 81: 43-51.

7 Tahara E. Growth factors and oncogenes in human gastrointestinal carcinomas. $\mathcal{F}$ Cancer Res Clin Oncol 1990; 116: 121-31.

8 Jankowski J, McMenemin R, Hopwood D, Penston J, Wormsley KG. Abnormal expression of growth regulatory peptides in Barrett's mucosa. Clin Sci 1991; 81: 663-8.

9 Kelly SM, Hunter JO. Epidermal growth factor stimulates synthesis and secretion of mucus glycoproteins in human synthesis and secretion of mucus glyco
gastric mucosa. Clin Sci 1990; 79: $425-7$.

10 Laurence DJR, Gusterson BA. The epidermal growth factor. Tumor Biol 1990; 11: 229-61.

11 Oka Y, Orth DN. Human plasma epidermal growth factor/ beta urogastrone is associated with blood platelets. $\mathcal{F}$ Clin Invest 1983; 72: 249-59.

12 Carpenter G, Cohen S. Epidermal growth factor; a minireview. F Biol Chem 1990; 265: 7709-12.

13 Mahida YR, Jones PDE, Daneshmend TK, Hawkey CJ. Peptide regulatory factors in the gut. In: Pounder RE, ed. Recent advances in gastroenterology. Edinburgh: Churchill Livingstone, 1990: 200-45.

14 Wright NA, Poulsom R, Stamp GWH, Hall PA, Jaffrey RE, Longcroft JM, et al. Epidermal growth factor (EGF/URO) induces expression of regulatory peptides in damaged induces expression of regulatory peptides in damaged

15 Tsuijkawa T, Bamba T, Hosoda S. The trophic effect of epidermal growth factor on morphological changes and
polyamine metabolism in the small intestine of rats. polyamine metabolism in the small
Gastroenterol fpn 1990; 25: 328-34.

16 Reiss M, Sartorelli A. Regulation of growth and differentiation of human kerantinocytes by type B transforming growth factor and epidermal growth factor. Cancer Res 1987; 47 6705-9.

17 Chernoff EA, Robertson S. Epidermal growth factor and th onset of epithelial epidermal wound healing. Tissue Cell 1990; 22: 123-35.

18 Cutry AF, Kinniburgh AJ, Krabak MJ, Hui Sek-Wen, Wenner CE. Induction of c-fos and c-myc proto-oncogene expression by epidermal growth factor and transforming growth factor alpha is calcium independent. $f$ Biol Chem 1989; 264: 19700-5.

19 Mukaida H, Yamamoto T, Hirai T, Toi M, Nakamura T, Yamashita Y, et al. Expression of human epidermal growth factor and its receptor in esophageal cancer. F p 7 f Surg 1990 29: $275-82$.

20 Onda M, Tokunaga A, Nishi K, Yoshiyuki T, Shimizu Y, Kiyama $\mathrm{T}$, et al. The correlation of epidermal growth factor with invasion and metastasis in human gastric cancer. $f_{p n} \mathcal{J}$ Surg 1990; 20: 269-74.

21 Nakagawa S, Yoshida S, Hirao Y, Kasuga S, Fuwa T Biological effects of biosynthetic human EGF on the growth of mammalian cells in vitro. Differentiation 1985; 29: 284-8.

22 Majumdar AP, Arlow FL. Aging: altered responsiveness of gastric mucosa to epidermal growth factor. Am $\mathcal{F}$ Physiol 1989; 257: 554-60.

23 Kunizaki C, Sugiyama M, Tsuchiya S. Epidermal growth factor inhibits cysteamine-induced duodenal ulcers in rats. Scand $\mathcal{F}$ Gastroenterol 1989; 162 (suppl): 218-21.

24 Konturek SJ, Dembinski A, Warzecha Z, Brzozowski T Gregory $\mathrm{H}$. Role of epidermal growth factor in healing of chronic gastroduodenal ulcers in rats. Gastroenterology 1988 ; 94: 1300-7.

25 Goodlad RA, Wright NA. Modulation of cell turnover and mucosal growth. In: Garner A, Whittle BJR, eds. Advances
in drug therapy of gastrointestinal ulceration. London: John in drug therapy of gastr.

26 O'Keefe EJ, Chiu ML. Stimulation of thymidine incorpora- 
tion in keratinocytes by insulin, epidermal growth factor, and placental extract: comparison with cell number to assess growth. F Invest Dermatol 1988; 90: 2-8.

27 Maccini DM, Veit BC. Salivary epidermal growth factor in patients with and without acid peptic disease. Gastropatients with and without
enterology 1990; 85: 1102-4.

28 Kingsnorth AN, Smith P, Richards RC. Parotid salivary epidermal growth factor levels in human reflux oesophagitis

29 Jankowski J, Austin W, Howat K, Coghill G, Murphy S, Hopwood $\mathrm{D}$, et al. Proliferation in the oesophagus; an index of chronological age. Eur $\mathcal{F}$ Gastroenterol Hepatol 1991; 3 675-8.

30 Livstone E, Sheahan D, Behar J. Studies of esophageal cel proliferation in patients with reflux esophagitis. Gastroenterology 1977; 73: 1315-9.

31 Starkey RH, Orth DN. Radioimmunoassay of human epidermal growth factor (urogastrone). $\mathcal{F}$ Clin Endocrino Metab 1987; 45: 1144-53.

32 Winkler ME, O'Connor L, Winget M, Fendley B. Epiderma growth factor and transforming growth factor alpha bind growth factor and transforming growth factor alpha bind differently to the epidermal

33 Coghill G, Swanson-Beck J, Gibbs JH, Fawkes RS. The avidin-biotin technique in immunocytochemical staining. In: Grange JM, Fox A, Morgan NL, eds. Immunological techniques in microbiology. Edinburgh: Society for applied bacteriology, technical series. 1987; 24: 87-110

34 Filipe MI. The histochemistry of intestinal mucins. Change in disease. In: Whitehead $R$, ed. Gastrointestinal and oesophageal pathology. Edinburgh: Churchill Livingstone, 1989: 65-91.

35 Jarvis LR, Dent J, Whitehead R. Morphometric assessment of reflux oesophagitis in fibreoptic biopsy specimens. 7 Clin Pathol 1985; 36: 44-8.

36 Hamilton SR. Adenocarcinoma in Barrett's oesophagus. In Whitehead R, ed. Gastrointestinal and oesophageal pathology. Whitehead R, ed. Gastrointestinal and oesophageal pat

37 Riddell RH, Golman H, Ransohoff DF, Appelman HD, Fenoglio CM, Haggitt RC, et al. Dysplasia in inflammatory bowel disease: standardized classification with provisiona clinical applications. Hum Pathol 1983; 14: 931-68.

38 Ishii M, Vroman B, LaRusso NF. Morphologic demonstration of receptor-mediated endocytosis of epidermal growth facto by isolated bile duct epithelial cells. Gastroenterology 1990 98: 1284-91
39 Yoshioka K, Takemura T, Murakami K, Akano N, Matsubara K, Aya N, et al. Identification and localisation of epidermal growth factor and its receptor in the human glomerulus. Lab Invest 1990; 63: 189-96.

40 Shirasuna $K$, Hayashido $Y$, Sugiyama $M$, Yoshioka $H$ Matsuya T. Immunohistochemical localisation of epiderma growth factor (EGF) and EGF receptor in human oral growth factor (EGF) and EGF receptor in human ora mucosa

41 Goodlad RA, Wilson TGJ, Lenton W, Gregory H, McCullagh KG, Wright NA. Proliferative effects of urogastrone-EGF on the intestinal epithelium. Gut 1987; 28 (suppl 1): 37-43.

42 Lee DC, Han VKM. Expression of growth factors and their receptors in development. In: Sporn MB, Roberts AB, eds. Peptide growth factors and their receptors II. London Springer-Verlag, 1990: 330-60.

43 Ozawa S, Ueda M, Ando N, Osahiko A, Shimizu N. High incidence of EGF receptor hyperproduction in esophagea squamous-cell carcinomas. Int $\mathcal{f}$ Cancer $1987 ; 39: 33-7$

44 Jankowski J, Murphy S, Coghill G, Grant A, Hopwood D, Wormsley KG. Expression of epidermal growth factor Wormsley KG. Expression of epidermal growth factor

45 Reid BJ, Haggitt RC, Rubin CE, Rabinovitch PS. Barrett' esophagus: correlation between flow cytometry and histology in detection of patients at risk for adenocarcinoma. Gastroenterology 1987; 93: 1-11.

46 Konturek SJ, Dembinski A, Warzecha Z, Bielanski W, Brzozowski T, Drozdowicz D. Epidermal growth facto (EGF) in the gastroprotective and ulcer healing actions of colloidal bismuth subcitrate (De-Nol) in rats. Gut 1986; 29 894-902.

47 Gysin B, Muller RK, Otten U, Fischli AE. Epidermal growth factor content of submandibular glands is increased in rats with experimentally induced gastric lesions. Scand $\mathcal{F}$ Gastroenterol 1988; 23: 665-71.

48 Tahara E. Growth factors and oncogenes in human gastrointestinal carcinomas. $\mathcal{F}$ Cancer Res Clin Oncol 1990; 116: 121-31.

49 Yoshida K, Kyo E, Tsujino T, Sano T, Niimoto M, Tahara E. Expression of epidermal growth factor, transforming growth factor alpha and their receptor genes in human gastric carcinomas; implication for autocrine growth. Fpn $\mathcal{f}$ Cance Res 1990; 81: 43-51.

50 Jankowski J, Hopwood D, Wormsley KG. Expression of EGF, TGF alpha and their receptors in the upper alimentary tract. Dig Dis (in press) 